\title{
LA DENUNCIA EN EL ANTEPROYECTO DE LEY DE PROCEDIMIENTO ADMINISTRATIVO COMÚN DE LAS ADMINISTRACIONES PÚBLICAS
}

\author{
Felio José Bauzá Martorell \\ Profesor titular (acreditado Aneca) de Derecho Administrativo \\ Universidad de las Islas Baleares \\ fbauza@fbauzaabogados.es
}

SUMARIO

\begin{abstract}
I.- PLANTEAMIENTO. II.- EVOLUCIÓN LEGISLATIVA DE LA DENUNCIA. III.- RÉGIMEN DE LA DENUNCIA EN EL ANTEPROYECTO DE LEY. 1.- Definición. 2.- Contenido. 3.- Cláusula de clemencia. A.- Motivación y perjuicio patrimonial. B.- Exención y reducción de sanción. 4.- El denunciante no es interesado en el procedimiento administrativo. IV.- LO QUE NO REGULA EL ANTEPROYECTO DE LEY EN MATERIA DE DENUNCIA.
\end{abstract}

\section{I.- PLANTEAMIENTO}

El anteproyecto de ley de procedimiento administrativo común de las Administraciones Públicas, aprobado en sesión del Consejo de Ministros de 8 de mayo de 2015 para su remisión a las Cortes Generales, introduce una importante novedad en materia de procedimiento sancionador, cual es la regulación de la denuncia.

Tradicionalmente en sede administrativa se ha considerado a la denuncia como una actuación-verbal o escrita- de un particular, cuyo efecto no es otro que la puesta en conocimiento de la Administración de un hecho que pudiera ser constitutivo de infracción administrativa, de ahí su inevitable conexión con el procedimiento sancionador.

No obstante lo anterior, la relación de la denuncia con el procedimiento administrativo no deja de ser sui generis, por cuanto -si bien pueda dar lugar al inicio del procedimiento- la misma no forma parte del procedimiento, de manera que se quedan en una especie de limbo jurídico en el que pocas veces las leyes sectoriales precisan la esfera de derechos y obligaciones que tiene a su alrededor: así, en ocasiones existe un deber de denunciar y otras veces no; algunas normas especiales se aseguran del tratamiento confidencial de la denuncia; el denunciante no es interesado en el procedimiento, si bien la Ley 2/1998, del País Vasco sí reconoce esta condición al denunciante; históricamente en materia tributaria se ha reconocido la condición de interesado del denunciante por tener derecho a cobrar un porcentaje de la sanción económica; en algunos ámbitos como el urbanístico, la denuncia se confunde con la acción pública; el ordenamiento es incapaz de dar un tratamiento a la denuncia anónima, que -por un ladoexige la identificación del denunciante, si bien se admite la denuncia anónima interpretando que el procedimiento se inicia por propia iniciativa y no por denuncia... en fin la denuncia no deja de ser una institución no exenta de polémica, como tantas cosas, construida a golpe de sentencia y de dictamen, y en la que el legislador ha prestado muy poca atención.

Sin resolver prácticamente ninguno de los problemas planteados, el anteproyecto de ley de procedimiento administrativo común de las Administraciones Públicas dedica un artículo, el 89, al inicio del procedimiento por denuncia, en el que introduce -importado del derecho americano y especialmente del ámbito de la defensa de la competencia-, el denominado programa de clemencia, que consiste a grandes rasgos en eximir de sanción al denunciante. 


\section{II.- EVOLUCIÓN LEGISLATIVA DE LA DENUNCIA}

No resulta exagerado advertir que el interés del legislador en la denuncia en los últimos ciento cincuenta años ha sido prácticamente nulo, y ello a pesar de la cantidad de problemas que ha generado una materia tan sensible al derecho de defensa y al ejercicio del poder punitivo, y sin perjuicio de que no ha existido duda de la cualidad garantista del procedimiento administrativo'.

En efecto si nos remontamos a la Ley Azcárate de $1889^{2}$, podemos apreciar que en su art. 2 contempla como documentos que puede dirigir un particular a la Administración la solicitud, exposición, instancia, comunicación u oficio, sin hacer mención alguna a la denuncia. Se trata ciertamente de una referencia omnicomprensiva, semejante mutatis mutandis a la pretensión de generalidad que hace Guido ZANOBINI para definir el acto administrativo3, en la que el intérprete del Derecho puede incluir a la denuncia en la exposición o la comunicación, si bien tampoco esta norma presta la más mínima atención a regular las bases de ninguno de estos documentos.

Con fundamentación jurídica en estas bases, entre 1889 y 1925 se dictan los reglamentos ministeriales para sus dependencias centrales, provinciales y locales, generando una dispersión normativa que la doctrina censuró con ahínco ${ }^{4}$.

La Ley de Procedimiento Administrativo de $1958^{5}$ introduce en el ordenamiento jurídico la denuncia cuando sistematiza el inicio del procedimiento de oficio en torno a cuatro causas: la propia iniciativa, la orden superior, la moción razonada de los subordinados y la denuncia (art. 68).

Y una redacción muy similar es la que hace suya el legislador de 1992 en el artículo 69 de la LRJPAC cuando señala que el procedimiento administrativo se inicia de oficio, bien por propia iniciativa o como consecuencia de orden superior, a petición razonada de otros órganos o por denuncia.

Resulta sin embargo paradójico que, pese a reconocer la existencia de esta institución, el legislador no dedica una sola palabra a regular la denuncia en una norma de referencia como es la Ley del procedimiento administrativo común. En todo caso, es el Reglamento 1390/1993 el que define la denuncia en su art. 11.1.d como "el acto por el que cualquier persona, en cumplimiento o no de una obligación legal, pone en conocimiento de un órgano administrativo la existencia de un determinado hecho que pudiera constituir infracción administrativa".

Asimismo la legislación sectorial en materia tributaria, de inspección de trabajo y seguridad social, y tráfico ha regulado alguna especialidad, aunque hasta la fecha no existe norma vigente que de forma exhaustiva regule la denuncia.

En este panorama de orfandad aparece el anteproyecto de Ley de procedimiento administrativo común de las Administraciones Públicas, en cuya defensa debe admitirse que, siguiendo la misma estructura de sus dos normas precedentes, afronta la regulación de las distintas formas de iniciar el procedimiento administrativo de oficio: propia iniciativa (art. 86), orden superior (art. 87), petición razonada de otros órganos (art. 88) y denuncia (art. 89).

\section{III.- RÉGIMEN DE LA DENUNCIA EN EL ANTEPROYECTO DE LEY}

\section{1.- Definición}

El legislador de Cortes Generales sí pasa a definir la denuncia en el anteproyecto de ley (art. 89), haciendo acopio de una redacción muy similar a la del art. 11.1.d del Reglamento de procedimiento sancionador, si bien el acto que se denuncia ya no tiene que ser susceptible de constituir una infracción administrativa, sino que en todo caso debe poder justificar "la iniciación de oficio de un procedimiento administrativo".

Como puede apreciarse la diferencia no es sustancial, sino meramente de redacción: el hecho denunciado que hace posible que se inicie de oficio un procedimiento sólo puede ser un hecho susceptible de ser constitutivo de infracción.

1 ROYO VILLANOVA, S. “El procedimiento administrativo como garantía jurídica”, Revista de Estudios Políticos núm. 48. Madrid, 1949. Págs. 55 a 120.

2 Ley de Bases para la redacción de Reglamentos de procedimiento administrativo de los Departamentos ministeriales, de 19 de octubre de 1889. Gaceta de Madrid núm. 298. Viernes 25 de octubre de 1889. Tomo IV. Pág. 237.

3 ZANOBINI, G. Corso di Diritto Amministrativo. Milán, 1954. Pág. 311.

4 GASCÓN MARÍN, J. “Necesidad de un código de procedimiento administrativo”, Revista de Estudios Políticos núm. 48. Madrid, 1949. Págs. 11 a 40 .

$5 \quad$ Ley de 17 de julio de 1958, de Procedimiento Administrativo. BOE núm. 171, de 18 de julio de 1958.

6 "Se entiende por denuncia el acto por el que cualquier persona, en cumplimiento o no de una obligación legal, pone en conocimiento de un órgano administrativo la existencia de un hecho que pudiera justificar la iniciación de oficio de un procedimiento administrativo". 
Por otro lado, no especifica este precepto que el procedimiento administrativo que puede iniciar de oficio el órgano es un procedimiento sancionador, cuestión que va de suyo porque la denuncia va unida indisolublemente al ejercicio de la potestad sancionadora.

\section{2.- Contenido}

En su punto segundo el art. 89 determina el contenido de la denuncia, con un requisito subjetivo y otro objetivo: así, por un lado exige la expresión de la identidad de la persona o personas que la presentan, y, por otro, el relato de los hechos que se ponen en conocimiento de la Administración.

Hasta aquí la regulación no es distinta del art. 11.1.2 del Real Decreto 1398/1990, que a lo anterior añade la fecha de su comisión y, cuando sea posible, la identificación de los presuntos responsables. Sin embargo, el anteproyecto incorpora una variación a la regulación vigente, y es que literalmente señala que "cuando dichos hechos pudieran constituir una infracción administrativa, recogerán la fecha de su comisión y, cuando sea posible, la identificación de los presuntos responsables".

El legislador exige un dato que no siempre puede obtenerse, cual es el elemento temporal del hecho constitutivo de infracción. Obsérvese que la norma reconoce la seguridad de conocer este dato, porque no en vano lo distingue del dato eventual de la identificación del supuesto infractor. Sin embargo, no se plantea el legislador si la omisión de la fecha de comisión de la infracción hace inviable jurídicamente la denuncia, porque no contiene ese requisito necesario; o si por el contrario la denuncia que no contiene la fecha de comisión del hecho, bien porque carece de ella, bien porque no puede de ningún modo obtenerla, se reconduce -como la denuncia anónima- a que se inicie el procedimiento por propia iniciativa, porque el art. 86 del anteproyecto, relativo al inicio del procedimiento a propia iniciativa, no hace referencia alguna al momento temporal de comisión de la infracción?.

\section{3.- Cláusula de clemencia}

En el punto tercero del art. 89 el legislador hace acopio de una fórmula importada de estados Unidos a Europa para el sector específico de la defensa de la competencia ${ }^{8}$, que ahora se hace extensiva al procedimiento administrativo común: la cláusula de clemencia.

\section{A.- Motivación y perjuicio patrimonial.}

Hasta ahora el Real Decreto 1398/1993 insiste en que la denuncia -por no formar parte del procedimiento administrativo- no vincula al órgano administrativo, si bien obliga a comunicar al denunciante la iniciación o no del procedimiento cuando la denuncia vaya acompañada de una solicitud de iniciación.

En este sentido el RPS distingue la denuncia tal cual, de la denuncia con vocación procedimental, porque va acompañada de una solicitud de inicio del procedimiento sancionador. La verdad es que esta distinción carece de mucho sentido, porque la intención del denunciante es que se corrija por parte de la Administración el hecho infractor, de ahí que -aunque no se acompañe de tal solicitud- la denuncia persigue el mismo fin en cualquier caso.

La novedad en este punto es que el anteproyecto pasa a exigir la motivación de la no iniciación del procedimiento (y su correspondiente notificación al denunciante) "cuando la denuncia invocara un perjuicio en el patrimonio de las Administraciones Públicas”, permitiendo interpretar que en el resto de casos, es decir, cuando no exista tal perjuicio patrimonial, la no iniciación del procedimiento no necesita ser motivada ni notificada al denunciante.

\section{B.- Exención y reducción de sanción.}

Más novedoso que lo anterior, este anteproyecto de ley, como decimos, incorpora la cláusula de clemencia al procedimiento sancionador, circunscrita (por razones de sistemática) a las infracciones que causen un perjuicio patrimonial a la Administración.

La cláusula de clemencia consiste en la exención de la sanción (ya sea pecuniaria o no) al denunciante que, siendo responsable de la infracción por haber participado en su comisión junto a otros infractores, sea el primero en aportar elementos de prueba que permitan iniciar el procedimiento o comprobar la infracción, siempre y cuando en el momento de aportarse aquellos no se disponga de elementos suficientes para ordenar la misma y se repare el perjuicio causado.

Como puede apreciarse, la aplicación de la clemencia no se realiza de forma ilimitada, sino que se somete a una serie de requisitos: (1) el denunciante tiene que ser infractor, (2) la infracción debe causar un perjuicio patrimo-

7 Se entiende por propia iniciativa la actuación derivada del conocimiento directo o indirecto de las circunstancias, conductas o hechos objeto del procedimiento por el órgano que tiene atribuida la competencia de iniciación.

8 SORIANO, J. E. La defensa de la competencia en España. lustel. Madrid, 2007. Págs. 213 y ss. 
nial a la Administración, (3) debe haber otros infractores, (4) el denunciante debe ser el primero en aportar pruebas en el procedimiento sancionador, y (5) en ese instante la Administración tiene que necesitar la información contenida en la denuncia para poder proceder al inicio del procedimiento, en el sentido de que la denuncia debe de aportar un valor añadido.

Un segundo nivel de clemencia consiste no en la exención, sino en la reducción de la sanción cuando -no cumpliéndose alguno de los requisitos exigidos para la exención- el denunciante facilite elementos de prueba que aporten un valor añadido significativo respecto de aquellos de los que se disponga, cese en la participación de la infracción y no haya destruido elementos de prueba relacionados con el objeto de la denuncia.

No obstante, estos límites de la clemencia contrastan sobre manera con el carácter reglado que el legislador confiere a esta cláusula, de manera que no permite en modo alguno la ponderación de las circunstancias. En efecto la redacción del art. 89 del anteproyecto obliga al órgano ("en todo caso" y "deberá") a eximir al denunciante la sanción o, en todo caso, a reducirla. En el alcance de la reducción puede existir la discrecionalidad, pero siempre el órgano administrativo estará obligado a ella si se dan los requisitos que enumera este precepto.

La cláusula de clemencia tiene sentido en un ordenamiento como el americano, y en un sector-incluso en derecho europeo- como el de la defensa de la competencia. Importar una institución sin su correspondiente adaptación y hacerla extensiva al procedimiento administrativo común, máxime sin permitir la valoración de la casuística, quiebra por completo el principio de seguridad jurídica.

Esta cláusula puede provocar un efecto radicalmente distinto del pretendido, que no es otro que incentivar la comisión de infracciones, sabiendo que la denuncia al resto de infractores conllevará la impunidad frente a la responsabilidad por el hecho infractor. Tratándose de infracciones que generan perjuicio patrimonial a la Administración, al denunciante le resultará rentable infringir, anulándose por completo el principio general del art. 131.2 LRJ-PAC de que la comisión de las infracciones tipificadas no resulte más beneficiosa para el infractor que el cumplimiento de las normas infringidas.

La valoración crítica de esta regulación no se ciñe tanto a la aplicación de la cláusula en sí, cuanto en el hecho de imponerla sin más, de obligar al operador jurídico a exonerar o reducir la sanción sin valorar, por ejemplo, una predeterminación a infringir, o la reincidencia en la misma conducta. El principio de proporcionalidad, independientemente de su positivización", como tal principio general e informador, exige la adecuación -a la hora de imponer una sanción- entre la gravedad del hecho constitutivo de la infracción y la sanción aplicada, debiendo graduar esta última en función de la existencia de intencionalidad o reiteración, la naturaleza de los perjuicios causados, y la reincidencia (art. 138 LRJ-PAC).

Esta aniquilación de la graduación y la proporcionalidad puede conllevar el escenario no ya de la reincidencia en la misma infracción, sino la reincidencia en beneficiarse de la cláusula de clemencia, convirtiendo al infractor en experto en infringir, denunciar a los demás infractores y exonerarse de la infracción; todas las veces que quiera, y sin que el intérprete del Derecho pueda hacer otra cosa que consentir el negocio de las infracciones y que se rían de la Administración y de toda la colectividad.

El Consejo de Estado en su Dictamen 275/2015, de 29 de abril de 2015, recomienda una reconsideración general de la iniciativa constituida por el anteproyecto de ley de procedimiento administrativo común de las Administraciones Públicas. De forma particular en relación al art. 89, no sin antes valorar la utilidad de la cláusula de clemencia, critica su regulación como mecanismo de aplicación genérica dentro del procedimiento administrativo común, advirtiendo que puede colisionar con lo dispuesto en las leyes sectoriales en las que se regula tal procedimiento (protección de datos, defensa de la competencia, ámbito tributario):

se trata de un mecanismo eficaz para incentivar la denuncia de infracciones y, con ello, facilitar su detección y sanción. Sin embargo, su extensión, de forma global y generalizada, a todos los procedimientos sancionadores, impide atender a las peculiaridades que por razón de la materia puedan existir en cada caso, lo que hace preferible mantener la regulación de este procedimiento en la legislación sectorial. Se recomienda por ello valorar la conveniencia de introducir una regla de este tipo en la ley reguladora del procedimiento administrativo común.

9 CARLÓN RUIZ, M. “El principio de proporcionalidad” En SANTAMARÍA PASTOR, J. A. Los principios jurídicos del derecho administrativo. La Ley. Madrid, 2013. Pág. 216. 


\section{4.- El denunciante no es interesado en el procedimiento}

En su punto cuarto, el art. 89 del anteproyecto de ley reitera una cuestión pacífica en el ordenamiento jurídico, y es que la presentación de una denuncia no confiere por sí sola la condición de interesado en el procedimiento.

Tradicionalmente en sede sectorial el derecho positivo ha recalcado que la denuncia no convierte a su autor en interesado en el procedimiento administrativo que la denuncia active (art. 4.5 del Real Decreto 1392/1993, art. 232 LGT... ) y la jurisprudencia igualmente considera consolidada la falta de legitimación del denunciante (vid. por todas, la Sentencia del Tribunal Supremo, Sala Tercera, de lo Contencioso-administrativo, Sección $6^{\text {a }}$, de 6 de octubre de 209 (rec. 4712/2005), FD 6).

No supone novedad alguna en consecuencia el texto del anteproyecto en relación a este punto, sin perjuicio -no lo indica el art. 89- de que el denunciante ostente derechos subjetivos e intereses legítimos que sí le otorguen por razones obvias la cualidad de interesado.

\section{IV.- LO QUE NO REGULA EL ANTEPROYECTO DE LEY EN MATERIA DE DENUNCIA}

En el seminario sobre la reforma del Estado organizado en el Instituto Nacional de Administración Pública (INAP) el día 12 de junio de 2015 se puso de relieve que -antes que las novedades- merecen mayor atención los silencios que guarda el anteproyecto de ley en relación a materias o aspectos que debiera regular.

En primer lugar y con carácter general, pese a una reforma del régimen jurídico del procedimiento administrativo común, seguimos en España huérfanos de una teoría general del derecho administrativo sancionador tal y como viene siendo demandada por la doctrina desde antiguo ${ }^{10}$.

En segundo término seguimos sin saber qué hacer ante la denuncia anónima. El anteproyecto exige la necesidad de identificar al denunciante, si bien omite la consecuencia jurídica de la omisión de tal dato. Cuesta entender la alergia de la ley de procedimiento administrativo común a prohibir la denuncia anónima cuando otras normas especiales ya vedan esta posibilidad (inspección de trabajo y seguridad social ${ }^{11}$, tráfico ${ }^{12}$ ).

Tercero. El estatuto jurídico del denunciante sigue siendo fruto de la labor interpretativa del operador jurídico, renunciando el legislador a una magnífica oportunidad de clarificar la posición del denunciante en el procedimiento, sus derechos y obligaciones ${ }^{13}$.

En cuarto lugar la vieja discusión en torno al principio dispositivo de la Administración sigue sin resolverse, en el sentido de si la Administración se encuentra obligada a tramitar una denuncia o no, que tiene su correlativo para el denunciante en si existe obligación o no de denunciar ${ }^{14}$.

En definitiva la valoración que se efectúa del anteproyecto de ley de procedimiento administrativo común de las Administraciones Públicas, al menos en lo que afecta al régimen de la denuncia, es que se trata de un texto manifiestamente mejorable. A favor debe admitirse que por vez primera en derecho histórico el legislador se toma en serio la denuncia y regula algunos de sus aspectos; si bien en contra debe advertirse del peligro que encierra el régimen reglado de la exención y reducción de sanciones al margen de la elemental ponderación del intérprete del Derecho, todo ello sin perjuicio de la necesidad de acometer las lagunas que siguen existiendo, recordando una vez más la necesidad de contar en nuestro país con una teoría general del derecho sancionador.

\section{BIBLIOGRAFÍA}

ALARCÓN SOTOMAYOR, L.; BUENO ARMIJO, A. M.; RODRÍGUEZ PORTUGUÉS, M. A.; REBOLLO PUIG, M. “Derecho administrativo sancionador”, Revista Española de Derecho Administrativo núm. 164. Págs. 157 a 173.

10 NIETO, A. Derecho administrativo sancionador. Tecnos. Quinta edición. Madrid, 2012. Págs. 18 y 19. ALARCÓN SOTOMAYOR, L. -BUENO ARMIJO, A. M. -RODRÍGUEZ PORTUGUÉS, M. A. -REBOLLO PUIG, M. "Derecho administrativo sancionador" Revista Española de Derecho Administrativo núm. 164. Págs. 157 a 173. SUAY RINCÓN, J. “La potestad sancionadora de la Administración y sus exigencias actuales: un estudio preliminar" Documentación administrativa núm. 280-281. Pág. 43.

11 Artículo 13.2 de la Ley 42/1997 y artículo 9.1.f del Real Decreto 928/1998.

12 Artículo 9.2 del Real Decreto 320/1994.

13 MARTÍNEZ YÁÑEZ, N. M. "Problemas jurídico-prácticos de la figura del denunciante en el procedimiento administrativo sancionador” Revista Xurídica Galega núm. 33. 2001. Pág. 64. DOMíNGUEZ LUIS, C. “Reflexiones en torno al status jurídico del denunciante en el procedimiento administrativo sancionador" Revista Jurídica de la Comunidad de Madrid núm. 21. 1 de mayo de 2005.

14 REBOLLO PUIG, M. "Interesados y denunciantes en el procedimiento administrativo sancionador". En BARNÉS VÁZQUEZ, J. (Coord.) El procedimiento administrativo en el Derecho comparado. Civitas. Madrid, 1993. Pág. 226 y ss. Este mismo artículo doctrinal se publica en Revista del Poder Judicial núm. 29. Marzo, 1993. Pág. 59 y ss. LOZANO CUTANDA, B. "El principio de oficialidad de la acción sancionadora administrativa y las condiciones necesarias para garantizar su efectividad”. Revista de Administración Pública núm. 161. Mayo/agosto, 2003. Pág. 83 y ss. 
CARLÓN RUIZ, M. "El principio de proporcionalidad", En: SANTAMARÍA PASTOR, J. A. Los principios jurídicos del derecho administrativo. La Ley. Madrid, 2013.

DOMÍNGUEZ LUIS, C. "Reflexiones en torno al status jurídico del denunciante en el procedimiento administrativo sancionador" Revista Jurídica de la Comunidad de Madrid núm. 21. 1 de mayo de 2005.

GASCÓN MARÍN, J. "Necesidad de un código de procedimiento administrativo" Revista de Estudios Políticos núm. 48. Madrid, 1949. Págs. 11 a 40.

LOZANO CUTANDA, B. "El principio de oficialidad de la acción sancionadora administrativa y las condiciones necesarias para garantizar su efectividad”. Revista de Administración Pública núm. 161. Mayo/agosto, 2003. Pág. 83 y ss.

MARTíNEZ YÁÑEZ, N. M. "Problemas jurídico-prácticos de la figura del denunciante en el procedimiento administrativo sancionador" Revista Xurídica Galega núm. 33. 2001.

NIETO, A. Derecho administrativo sancionador. Tecnos. Quinta edición. Madrid, 2012.

REBOLLO PUIG, M. "Interesados y denunciantes en el procedimiento administrativo sancionador". En BARNÉS VÁZQUEZ, J. (Coord.) El procedimiento administrativo en el Derecho comparado. Civitas. Madrid, 1993. Pág. 226 y ss. Este mismo artículo doctrinal se publica en Revista del Poder Judicial núm. 29. Marzo, 1993. Pág. 59 y ss.

ROYO VILLANOVA, S. "El procedimiento administrativo como garantía jurídica" Revista de Estudios Políticos núm. 48. Madrid, 1949. Págs. 55 a 120.

SORIANO, J. E. La defensa de la competencia en España. lustel. Madrid, 2007.

SUAY RINCÓN, J. "La potestad sancionadora de la Administración y sus exigencias actuales: un estudio preliminar”, Documentación administrativa núm. 280-281. Pág. 43.

ZANOBINI, G. Corso di Diritto Amministrativo. Milán, 1954. 